\title{
MANAGING THE CURRENT SITUATION OF YOUNG PEOPLE IN NATIONAL AND EUROPEAN CONTEXT IN TERMS OF THEIR EMPLOYMENT
}

\author{
Lecturer Alexandra Patricia Braica PhD \\ „Vasile Goldis” Western University of Arad, Faculty of Economics \\ E-mail: alexandra.braica@gmail.com
}

(Received February 2015; accepted April 2015)

\begin{abstract}
Assessment and research into this phenomenon of social marginalization and social exclusion of young people at both national and European levels has as a target to find methods of prevention and reduction of this phenomenon and understand the fact that it is only through communication, debates and dialog that will we be able to establish benchmarks for joint action. Young people are one of the age segments which are most affected by the economic recession. It is also accepted that in each of the Member States of the EU, despite different circumstances and levels of economic development, major issues faced by young people are the same: from access to essential services (such as education and health) and up to their integration into the labour market with a view to achieving a higher standard of living. The decision makers are constantly interested in solving these stringent problems, which can be found in the policies and strategies for economic recovery and fighting the austerity measures adopted by the Member States of the EU, through a series of programs that have as main objectives combating unemployment and poverty among young people and providing opportunities for more active involvement in their community life: political, social, economic, cultural. In Romania, the problem of young people constitutes an issue of major importance for the Government, which has drawn up for the first time an Integrated Strategy of Romania with regard to young people called "National Strategy for Youth 2014-2020"1, with particular emphasis on the first role that education must play in this context. Examples of solutions identified by the governors are: an increase in public funding for mentoring programs, for the prevention of school dropout rates, establishment of differentiated educational offers, training schemes designed to eliminate lack of qualification in young people, in such a way as to maintain a competitive and well-prepared generation in the country.
\end{abstract}

Key words: Young people, strategy for youth, solutions, employment, jobs

\section{Introduction}

Assessment and research into this phenomenon of social marginalization and social exclusion of young people at both national and European levels has as a target to

${ }^{1}$ www.mts.ro/wpcontent/uploads/.../Strategie_22.10.2013_integrat_revOM.doc 
find methods of prevention and reduction of this phenomenon and understand the fact that it is only through communication, debates and dialog that will we be able to establish benchmarks for joint action.

Young people are one of the age segments which are most affected by the economic recession. It is also accepted that in each of the Member States of the EU, despite different circumstances and levels of economic development, major issues faced by young people are the same: from access to essential services (such as education and health) and up to their integration into the labour market with a view to achieving a higher standard of living.

It could be a "split" of the pact between generations, but rather a gap in communication and expectations, and maybe for some different visions. Let us not forget, however, that young people have a higher capacity to adjust to the new realities, and this has been noted in the framework of cooperation, for the exchange of information and different cultures between various organizations, the services of volunteers, program mobility, etc.

The decision makers are constantly interested in solving these stringent problems, which can be found in the policies and strategies for economic recovery and fighting the austerity measures adopted by the Member States of the EU, through a series of programs that have as main objectives combating unemployment and poverty among young people and providing opportunities for more active involvement in their community life: political, social, economic, cultural.

\section{Research Methodology}

In this paper, I used bibliographic sources in the field and I referred to specific legislation.

The methodology used throughout the research was conceptualization, identification of management elements applicable to conflict situations from the perspective of central public administration, at the institutional level where the conflict arises, with their rigorous adaptation. The research has a determining and experimental-formative character. The analysis, as an instrument for applicative research, was conducted through situations and statistics made at the level of central public administration, according to public data. Good results were yielded by the use of models, the study of official documents, legislation regulating this field in Romania, European norms, documents issued by diverse institutions and subject to transparency. The processing of data and information acquired by applying the instruments of research was carried out using software applications. I combined the theory reflecting, in a generalized form, the ideas, objectives, elements, concepts, principles defining the area of conflict management, the methodology approaching the methods, procedures of knowledge, research of the 
field, as well as specific action, managerial technology - which expresses, in essence, knowing how to do a concrete action rationally, efficiently, using theory and methodology, and practice - adapting above-mentioned elements to actual conditions.

The research required the study of specialized literature - economic, legal, sociological, psycho-sociological and pedagogical - which approached the issue of staff or human resources management, conflict management, labour law, as show in bibliographic references, with a direct impact in tackling the content pursued in the paper.

The research work consisted of: documentation, the study of organizational culture, the study of legal and practical aspects on labour legislation, mediation, statistic data processing and interpretation methods.

The involvement of the Social Dialogue Department within the Ministry of Labour, Family, Social Protection and Elderly, where I have been working for over two years, in such projects is opportune for conducting a program to develop alternative labour dispute resolutions, in order to decrease their negative effects.

\section{Results and discussions}

Assessment and research into this phenomenon of social marginalization and social exclusion of young people at both national and European levels has as a target to find methods of prevention and reduction of this phenomenon and understand the fact that it is only through communication, debates and dialog that will we be able to establish benchmarks for joint action.

Young people are one of the age segments which are most affected by the economic recession. It is also accepted that in each of the Member States of the EU, despite different circumstances and levels of economic development, major issues faced by young people are the same: from access to essential services (such as education and health) and up to their integration into the labour market with a view to achieving a higher standard of living.

It could be a "split" of the pact between generations, but rather a gap in communication and expectations, and maybe for some different visions. Let us not forget, however, that young people have a higher capacity to adjust to the new realities, and this has been noted in the framework of cooperation, for the exchange of information and different cultures between various organizations, the services of volunteers, program mobility, etc.

The decision makers are constantly interested in solving these stringent problems, which can be found in the policies and strategies for economic recovery and fighting the austerity measures adopted by the Member States of the EU, through a series of programs that have as main objectives combating unemployment and 
Managing the current situation of young people in national and European context in terms of their employment

poverty among young people and providing opportunities for more active involvement in their community life: political, social, economic, cultural.

In Romania, the problem of young people constitutes an issue of major importance for the Government, which has drawn up for the first time an Integrated Strategy of Romania with regard to young people called "National Strategy for Youth 2014 2020" (www.mts.ro/wpcontent/uploads/.../Strategie_22.10.2013_integrat_revOM. doc), with particular emphasis on the first role that education must play in this context. "The strategy aims to combat some of the specific issues of the labour market in Romania, such as massive employment in the informal sector, false employment in activities of subsistence on one's own account, workplace insecurity, wage poverty, lack of access to forms of continuing training for labour market and other forms of occupational exclusion; as a result of implementation, we are expecting a reduction in the incidence of these phenomena" (National Strategy for Youth 2014-2020, Government of Romania, Ministry of Labour, Family, Social Protection and Elderly (MMFPSPV) approved by G.D. no.1071/2013).

For implementation of this strategy, the development of educational packages, continuous and structured dialog with young people and their organizations, social partners (Defined under art1 of the Law no. 62/2011 Law of Social Dialogue), policy makers and business decision makers are essential elements with positive effects on the mobilization of the parties involved.

Examples of solutions identified by the governors are: an increase in public funding for mentoring programs, for the prevention of school dropout rates, establishment of differentiated educational offers, training schemes designed to eliminate lack of qualification in young people, in such a way as to maintain a competitive and well-prepared generation in the country.

It is worth noting that the state does not create direct jobs, but only ensures, through a simulative institutional framework, the economic environment necessary for job creation. Thus, the Ministry of Labour, Family, Social Protection and Elderly does not create jobs in the economy directly, this depending on the entrepreneurs and the business world. However the MLFSPE (Ministry of Labour, Family, Social Protection and Elderly) (Ministerul Muncii, al Familiei, Protectiei Sociale si Persoanelor Varstnice) key task is to adopt the most effective support measures to facilitate job creation by them and stimulate employment.

Policy makers, by policies that they shall draw up, are continuously concerned with the permanent integration of young people into the labour market and combating unemployment among them. As practical solutions to increase participation of young people in the labour market, we mention the following: 
$\checkmark$ implementing apprenticeship schemes as a way of training young people in accordance with professional aspirations and filling a job according to the needs of employers;

$\checkmark$ supporting internships, facilitating the access of young graduates of higher education on the labour market by a decent and sustainable job for properly completed studies;

$\checkmark$ stimulating employers for the employment of graduates by granting differentiated subsidies, depending on their level of studies.

$\checkmark$ promoting labour market participation of young people at risk of social exclusion by encouraging employers who hire young people in this category;

$\checkmark$ developing youth mobility by granting mobility awards in accordance with the first employments;

$\checkmark$ providing advice and assistance for starting an activity as self-employed persons, or for setting up a business;

$\checkmark$ providing free services for the assessment of competences acquired in ways other than formal ones and obtaining a certificate of skills recognized at the national level that allows filling a properly qualified job.

An important element (European Structural Founds) in the fight against high unemployment among young people is represented by European funds. In the ESF 2014-2020 programming, the future introduction of a dedicated priority axis, the "Youth Employment Initiative" (YEI) in the Operational Program Human Capital is considered for the 3 eligible regions in Romania (according to the data provided by the Ministry of European Funds, (http://www.fonduri-ue.ro). Measures will be implemented in these three regions, which have recorded unemployment rates above the level of 25\% in the year 2012, namely South-East, South and Centre; they will receive financing from YEI, in addition to ESF.

Romania intends to start implementing the measures financed from the YEI before approving the partnership agreement and prior transmission of future Human Capital Operational Program 2014-2020 by providing initial funding from the State budget.

The plan includes:

In the past year, 2014, The Implementation Plan for the Youth Guarantee placed particular emphasis on delivering combined measures of employment and training, including apprenticeships and traineeships for graduates. Partnerships represent the cornerstone of the entire set of reforms, measures and policy initiatives that will be undertaken under the scheme, and the basic approach, such as "bottom-up", integrates social partners representing both the segment of labour demand and supply, who will take initiatives, will enter into partnerships with the public employment services and the local authorities, will share resources including 
Braica, A.P., (2015)

Managing the current situation of young people in national and European context in terms of their employment

financial in order to achieve the common goal of integrating young people on the labour market and training activities.

Key Reforms and initiatives to ensure early intervention and activation:

- Creating an integrated database for the registration of young people in the National Employment Agency;

- Creating partnerships between NCDPTE (National Center for Development of Professional and Technical Education), school inspectorates, LABOUR OFFICES and schools in order to promote, through campaigns, measures for stimulating employment and participation of young people in vocational training and education;

- Development of self-service and outreach to local communities, especially rural ones;

- Implementation of the Second Chance program for primary education (Regards the support for 6,000 young people/adults aged over 14 years for the recovery of primary education);

- Implementation of the Second Chance program for lower secondary education (Regards the completion of basic education within compulsory education, as well as training to obtain a professional qualification in a certain field by 10,000 young people over 14 years who have not completed secondary education);

- Continuing to implement the National Program for the social protection of professional Scholarship;

- Continuing to implement the national program Money for high school.

Support measures for integration on the labour market:

- Counselling and vocational guidance;

- Boosting freelance employment and entrepreneurship for young people;

- Assessment and recognition of professional qualifications acquired in non-formal and informal systems;

- Vocational training;

- Granting mobility prizes;

- Subsidies to employers for the employment of young people;

- Providing personalized accompaniment to young people at risk of social exclusion;

- Development of entrepreneurial skills among young people and facilitating their access to funding -START (Program funded from the state budget, amounting to 30 million lei (reimbursable financial aid) for 2014-2015, coordinated by MFE (and the Ministry of Economy);

- Stimulation and development of micro-enterprises by the young entrepreneurs $S R L-D$ (Project funded from the state budget, for young entrepreneurs (beginners) to complete internships of up to la 6 month with experienced entrepreneurs in the 
EU, mentorships, strengthen competences required to initiate and develop own businesses);

- Mentoring young people who are accessing the Program for the development of micro-enterprises and stimulation by the young entrepreneurs;

- The project with external funding (the Erasmus project) Growing-Up II funded by the European Commission, within the framework of the Erasmus program (13,500 lei/person (equivalent of 3,000 euro/person).

Financing of measures in the implementation of the Security Plan for the Youth 2014-2015 is based on the following main sources:

- the unemployment insurance budget (BASS);

- ESF (European Social Fund) and other structural and cohesion instruments, if appropriate;

- YEI (Youth Employment Initiative) funds;

- State budget, including amounts representing co-financing for the absorption of funds from the EUROPEAN SOCIAL FUND and YEI (Initiative for Youth Employment).

For 2015, the employment program design was based on the Government Programme 2013-2016, goals and strategic objectives of the European Union in employment towards 2020, including the Youth Guarantee scheme for the period 2014-2015.

The principle behind the design of the program is equal access to employment services and incentives to employment without discrimination. Measures addressing persons belonging to disadvantaged groups in the labour market provided by legislation does not constitute discrimination.

The general objectives of the Employment Program for 2015 are:

a) Increasing employment opportunities and valuing the professional skills of persons seeking employment on the domestic labour market;

b) Preventing long-term unemployment;

c) Facilitating the transition from unemployment to employment.

The specific objectives of the program are primarily:

a) supporting the employment of persons belonging to disadvantaged populations;

b) stimulating the unemployed to fill a job;

c) guiding the unemployed to occupations and jobs required by local labour market and providing support in being included in appropriate training programs;

d) supporting and encouraging employers to fill vacancies through recruitment of people looking for a job, focusing on disadvantaged groups; 
e) promoting labour mobility in the structural changes occurring in the national economy;

f) supporting higher education graduates to gain work experience through professional internships, while also encouraging employers.

The Employment Program for 2015 (according to data provided by NEA, http://www.anofm.ro) was developed on the basis of proposals by county agencies and the Bucharest Agency for employment, proposals based on the analysis of the economic - social situation recorded at the local level.

Also taken into account were the results of implementing plans and programs in employment over the past year, the attractiveness of employment incentives and other fundamental elements such as:

- the level and structure of unemployment compensation forms on residential backgrounds, gender, age, level of training, territorial distribution of unemployment etc.;

- the number of staff working in the territorial agencies for employment;

- the evolution of vacancies reported by employers during the first 10 months of 2014, on an upward trend from the previous year;

- the unemployment forecast for 2015 conducted by the National Commission for Prognosis (http://www.cnp.ro)("Medium-term forecast 2014-2018, autumn forecast, November 2014") which shows a decrease in both the number of unemployed and the unemployment rate (from a number of 485,000 registered unemployed in early 2015 to 465,000 at the end of 2015 and an unemployment rate of $5.1 \%$ expected by the end of the year);

- the situation of unemployment inflows in 2014 (first 10 months).

This program was based on the strategic targets of the documents adopted at the national level, noting that it was not only the National Employment Agency that contributed to their achievement, even if it is a major player in the labour market, the efficiency of the Agency being directly dependent on conjectural indicators that regulate the labour market.

The normative acts underlying the program design and definition of key quantitative indicators are:

- Law no. 76/2002 on the unemployment insurance system and stimulating employment, as amended and supplemented, and the whole package of rules and procedures adopted for its implementation,

- Law no. 72/2007 on stimulating employment of pupils and students

- Law no. 335/2013 on internship for university graduates,

- Justification of the state social insurance budget for 2015. 
The measures to be implemented by the Employment Program for 2015 consider both segments of the labour market and consist of:

- providing free mediation services for vacancies or newly created jobs by providing information on available jobs and bringing together people looking for work with employers, preparing an individual mediation plan for each person, organizing general or specialized job fairs for specific target groups according to labour market needs. To do this, local agencies will work to develop partnership relations with employers, focusing on the quality of staff selection and distribution, in accordance with job requirements;

- providing free information and professional counselling services to individuals seeking employment by providing information on the labour market and evolution of occupations, appraisal and self-appraisal of personality for professional orientation, developing ability and confidence in people seeking employment, as well as training in methods and techniques to find a job;

- stimulating re-employment for the unemployed by complementing wages for unemployed persons who find employment before the expiry of unemployment, thus trying to prevent long-term unemployment among young people up to the age of 25 years and older adults, at risk of remaining unemployed for more than 6 months, and 12 months respectively;

- stimulating labour mobility by providing employment or installation bonuses, if applicable;

- organizing and enhancing training courses for people looking for a job, and ensuring that the graduation and employment rates are as high as possible;

- providing free consulting services and assistance in starting a new business in order to increase employment;

- granting subsidies to employers to hire persons belonging to disadvantaged categories or with a difficult access to the labour market: unemployed aged over 45, unemployed single parents, people who have five years until retirement, education graduates and graduates with disabilities, coupled with quality professional counselling for young people and persons with disabilities;

- providing custom accompaniment to young people at risk of social exclusion through solidarity contracts and provision of specific services, including by providing subsidies to employers who hire people in this category;

- helping higher education graduates with the transition from the education system to the labour market, by strengthening professional skills and abilities to adapt to practical requirements and demands of the workplace and for faster integration into employment, as well as acquiring experience and work seniority and, where appropriate, specialized seniority, by granting financial support to professional internship programs on the demand of employers. 
- stimulating employment of pupils and students during their summer holiday.

The Employment Program was designed to implement measures oriented towards balanced representation of all categories of people looking for a job, focusing on mediation, information and counselling/career guidance measures, the provision of customized packages of active employment measures, strengthening relations with the social partners.

Given the evolution of unemployed registered by the NEA (National Employment Agency (ANOFM)), the flows into and out of unemployment in recent years, the National Commission for Prognosis estimates on unemployment for 2015, the Agency aims to include at least 1,000,000 persons in programs of active measures in 2015. At least 673,915 people will fall in labour mediation services, and 443,545 people will receive information and counselling services. Another aim is that at least $35 \%$ of people who will fall in employment services $(350,000$ people) could be employed.

As a core service of the Agency (National Employment Agency (ANOFM)), labour mediation will be an important contribution to employment of registered persons, noting that, for people who require special intervention, this service will be accompanied by other services and employment incentives that will address both individuals and employers.

Thus it is expected that 298,855 persons, about $85 \%$ of the employment program, should be employed as a result of labour mediation, other 43,615 persons through information and counselling, and approximately 57,900 persons through other types of active measures (Provided both in Law no. 76/2002 on the unemployment insurance system and stimulation of employment, as amended and supplemented, Law no. 335/2013 on internships for higher education graduates, as well as Law no. $72 / 2007$ on the stimulation of employment for pupils and students). The number of persons to be employed and the types of measures financed directly from the unemployment insurance budget (physical indicators structured by counties) is as follows:

- 22,870 persons by encouraging employers to employ certain categories of persons:

- 15,335 persons by encouraging employers to hire people aged over 45 or unemployed single parents,

- 6,970 persons by encouraging employers to hire graduates of education,

- 355 people by encouraging employers to hire people who have five years until fulfilling legal requirements for retirement,

- 210 persons by encouraging employers to hire people with disabilities,

- 11,935 persons as a result of the use of skills obtained upon completion of training courses, 
- 15,280 persons by supplementing wages for unemployed people employed before the expiry of the period for receiving unemployment benefits, of which 1,090 unemployed among graduates of education,

- 2,365 persons by stimulating labour mobility,

- 3,350 graduates who benefit from employment bonus,

- 190 persons through consulting services and assistance to start a new business,

- 400 persons by encouraging employers in order for university graduates to pursue professional internships;

- 825 as a result of measures and services offered to young people in solidarity contracts (According to Law no. 76/2002 on the unemployment insurance system and stimulation of employment, as amended and supplemented).

The Employment program (Adopted by the Government of Romania) for 2015 is aimed at employment of persons who have difficult access to the labour market, such as: 5,385 Roma people; 490 people with disabilities; 200 young people leaving the child protection system; 15 people released from detention; 10 foreigners.

According the form of unemployment (compensated or uncompensated), the structure of persons to be employed by the program has been designed to ensure a balance between the two categories. Of the 350,000 persons proposed to be employed, $60 \%$ are uncompensated unemployed (209,770 persons), 39\% compensated unemployment (139,400 people) and almost 1\% (830) other people looking for a job in the records of the NEA (National Employment Agency (ANOFM)).

The program also provides employment for 10,870 long-term unemployed, of whom 4,455 are under 25 years, and 6,415 are long-term unemployed aged over 25 years.

For 2015, the program aims to provide employment for 148,815 women (approx. $42 \%$ of the program) and 201,185 men.

The structure by age categories of the program is consistent with the structure of the number of registered unemployed, by age, and provides employment to:

- 74,720 persons under 25 years ( $21.35 \%$ of the program),

- 87,320 persons between $25-35$ years (24.95\% of the program);

- 95,700 persons between $35-45$ years ( $27.34 \%$ of the program);

- 92,260 persons over 45 years (26.36\% of the program), of which 39,585 persons over 55 years.

As structured on backgrounds (urban or rural) program provides employment to 203,775 people in urban areas (58.22\% of total program) and 146,225 people in rural areas or $41.78 \%$ of the total program. This structure is determined by the greater supply of employment in urban areas. 
For 2015, in order to increase the employment rate of people in rural areas or in urban areas with social reintegration problems, the Employment program for 2015 included: Program 155 for 155 rural areas; Program 50 for 50 urban areas. The main criteria for establishing these areas were: the large share of unemployed in the total active population and the low level of economic development. Implementing these programs is expected to employ a total of 14,700 people or 4,500 people in rural areas and 10,200 people in urban areas.

Given that the NEA is involved in the implementation of the Governmental Strategy for Roma Inclusion 2012-2020 (approved by the Government of Romania) and given that one of the priorities for 2015 Agency is employment of Roma people, Program 145 was proposed, especially for communities with large numbers of Roma ethnics, which will be supported by actions carried out by the public employment service, such as: information regarding employment services in communities with large populations of Roma ethnics, actions to be performed within budget at the local level, job fairs and developing cooperation with Roma representatives. This special program is estimated to provide employment to 2,300 people, approx. $42 \%$ of the total number of Roma people proposed for employment in 2015 by the national program.

For 2015, the Special traineeship program was proposed for university graduates (as provided by Law no. 76/2002 on the unemployment insurance system and stimulation of employment, as amended and supplemented), providing employment to 400 young people, who the National Employment Agency would subsidise from the unemployment insurance fund (as provided by Law no. 335/2013, included in the Employment Program of the National Employment Agency). The Special internship program for university graduates for 2015 is divided into categories of young people. In these special programs, the focus is on customized actions, especially on labour mediation services, knowing that employment can be done on job vacancies reported by employers, under the law, and on professional counselling services, the quality of which depends on the orientation of persons seeking employment, either directly to available employment, or by association with other measures to support employment.

The National Employment Agency included a Special program for pupils and students in the Employment Program for 2015, supporting fixed-term employment (according to their level of training) for a maximum of 60 calendar days, during holidays, for students and pupils (in accordance with the provisions of Law no. $72 / 2007$ on the stimulation of employment for pupils and students). This program seeks to accustom pupils and students with workplace activities and obtaining income from employment. This program proposed the employment of 1,635 people during the holidays, out of which 990 pupils and 645 students. 
Managing the current situation of young people in national and European context in terms of their employment

We note the positive fact that the Employment Program also includes an employment program for young people at risk of social exclusion for 2015, subject to a distinct document as (provided by Law no. 76/2002 on the unemployment insurance system and stimulation of employment, as amended and supplemented). Given the qualifying criteria for the realization of ex-ante conditionalities applicable to the use of European Structural Funds, in particular the Human Capital Operational Programme, 2014-2020 programming period (According to data provided by MFE), conditionalities undertaken by the Government, the National Employment Agency will outsource part of specialized services to counties where prerequisites were identified for contracting accredited or certified service providers, as appropriate, in order to relieve staff from some of the burden. Not all counties have planned outsourcing of services. Depending on the needs and developments in the local labour market, this program may be modified so that it can provide customization and quality specialized services, especially for certain categories of people, such as Roma people, people with disabilities and so on.

For 2015 , it is expected that at least 12,335 people will be included in services for which outsourcing contracts are signed, while at least 2,870 people will be employed as a result of participation in these services.

The division of tasks in the Employment Program for each county was considered according to the following criteria: the number of unemployed in the records, unemployment rate and unemployment structure at the local level, trends and opportunities in the economic and social development in each county, the absorption capacity of the labour market according to the predominant industries in the county.

Active measures to stimulate employment proposed to be implemented have been provided funding from the unemployment insurance budget for 2015 (as proposed by the justification of the state social insurance budget project for 2015), with 242.4 million lei allocated, which is approx. $13 \%$ of the total annual spending budget.

To achieve quantitative indicators set out in the employment program, general compulsory actions are provided for all territorial structures of NEA (National Employment Agency county and Bucharest):

- media coverage, at least once a month, through various forms (mass media, round tables, seminars, visits to employers, etc.) of financial incentives and specialized support provided by the Agency to integrate people looking for a job, especially young university graduates, young people who may be enrolled in apprenticeship programs etc.;

- developing partnerships with relevant actors in the labour market resulting from partnerships undertaken either at national or local level, and implementing them to join efforts with the aim of integrating persons belonging to disadvantaged groups. 
From the experience they had to this date, those responsible (representatives of MMFPSPV) predict that the implementation of this program might encounter a number of difficulties:

- the reluctance of employers to the employment of vulnerable people in the labour market due to some legislative constraints, so that employers will turn their attention towards people with high qualifications and skills, as well as professional experience and full work capacity;

- the lack of work experience and low wages on employment, leading to long-term unemployment;

- the education system, based especially on theory, connection with practice in production being poorly represented during the education period.

Implementation of the Employment Program may also be affected by future developments in the labour market, cyclical developments in Romania, but also in Europe, budget allocations and possible corrections to the unemployment insurance fund. In this context, the program is flexible, with the possibility of changing it during the year.

Successful implementation of the program is largely determined, however, by the quality of collaboration with employers and local authorities, but also by the confidence of people in search of employment in the services provided by the National Employment Agency (in 2014, in Romania, 40,000 vacancies declared at NEA have remained unoccupied).

\section{What kind of solidarity measures should be taken to deal with demographic changes in Europe?}

An analysis of the national and European context shows unambiguously that the population undergoes a certain aging trend, both within the framework of the European Union, and in Romania.

At the same time, there is a tendency for youth to migrate from one country to another to find a better job.

These trends exert additional pressure on the budgets of social insurance in the countries in which the number of people at retirement age is increasing, and the population capable of work is declining.

Although migration can provide a momentary solution, on a short-term basis, to this problem, in the long term it may complicate the situation, given the lesser or greater cultural differences to the host country.

Therefore, a first step should aim to stimulate the economies of countries of origin to increase the enrolment of youth on labour market. 
Of course, this can only be done in conjunction with the education system to provide the necessary training and an adequate number of graduates for the economic sectors that need workers.

However, at the same time, in Europe we need a greater harmonization of the labour market, enabling migrant workers to adapt more easily to the challenges of living in another country and to effectively combat discrimination among people of different origins, but with comparable degrees of skill.

But to do this, there is a need for a radical change in current attitudes, which will require a longer time period. However, in this case, the educational system can provide adequate response by developing new training programs that focus on cultural diversity in society and focus more on the common human elements than national differences.

Also in this respect, it is necessary to maintain support for mobility programs existing at the EU level that allow young people to travel between universities or schools (Erasmus, Grundtvig, Leonardo), which will contribute to a change in perception, essential to the way in which will the demographic situation of Europe will be managed in the coming decades.

Also, at the level of the Member States, support should be given to a better and more active involvement of youth in politics, advocacy programs for dealing with the problems of young people, and participatory democracy, with an emphasis on explaining advantages of this concept for practical aspects of daily life of youth.

\section{Is the migration of young people elsewhere a solution to Europe's demographic challenge? How can young people express economic and social needs more efficiently and how can they be equipped to better cope with the labour market expectations?}

Migration of young people to other countries is an ad hoc solution to Europe's demographic challenge.

Though normally they would need to be supported more at the national level, economic realities cause them to look for work in other countries.

This is not in itself a positive or negative thing, but it can be evaluated from the point of view of benefits that they have acquired and bring to the host country.

This is closely linked to the legal status of workers who pay taxes in the countries where they operate, or lower status workers on the black market, which does not benefit anyone.

At this point, again, the educational system can have a decisive effect on the integration of young people into the labour market.

In addition to conventional education that young people can receive in their normal studies from the country of origin, we must have in mind those who are already in 
other countries and need training to better adapt to the requirements of the labour market of that country.

To the extent that it is possible (at EU level, at least), the (member State) of origin can organize formal or non-formal educational training sessions abroad, to give young people more opportunities to integrate into the society and to access jobs.

\section{Is there a need for a new intergenerational pact to counter the growing distortion of equitable distribution of resources between generations?}

In connection with this pact between generations, I think we must take into account the attenuation of the demographic issues through by the following:

- Consistent measures to stimulate the birth rate for employed women;

- Introducing financial incentives and to increasing maternity leave;

- Allocations of financial resources from the EU budget, as not all Member States have the same potential for economic development.

At the same time, each Member State may contribute to a more equitable distribution of resources through public funds at its disposal. I think it would be useful to make a short presentation of the contents of the three categories of public expenditure that are regulated at the level of the EU member states:

- The first group should include, child allowance (variable in some countries depending on the age of the child and/or parents' income), allowance during parental leave, the level of income for single parent families;

- The second category includes direct funding or subsidiary health services, preschool education, special financial support to parents for child care, public spending for youth assistance and services to the family;

- Tax deductions aim exemptions from taxes (taxation) for allowance and other child's financial benefits, tax allowance for children (the amount that is deducted from gross income and is not included in taxable income), tax credit (deducted from the tax base).

According to published sociology studies, there is a correlation between what the state provides as an economic support to families with children and the birth-rate level. Instead of using the birth-rate level, we are using a more synthetic and relevant indicator - the total fertility rate, meaning the average number of children that a woman gives birth to over a lifetime.

In countries that are at the top of the leader board by level of expenditures we find the highest fertility.

The correlation is not as close in the case of some countries in which the high level of expenditures is not associated with similar fertility: Germany, Austria, Czech Republic, Slovakia and - especially - Hungary. 
Perhaps some cultural patterns mark on family size for the first two countries, and political and social break consequences for the three ex-communist countries.

In the group of countries where the low level of public spending on family is associated with a similar fertility we find some economically developed western countries for a long time or which entered later in quickly modernization, and excommunist countries.

Shrinking the gap that has formed between generations, followed by the fact that older people have benefited from tax facilities, as well as compensation for some of the expenditures and a more generous treatment on the part of retirement, could be achieved by a negative trend of fiscal policies for the companies which employ young people, helping to reduce disparities in employment on the criterion of age.

A constant concern of the European Governments for the medium and long term should be constituted by adaptation to current economic realities, as it is no longer possible to ensure a generous social protection granted to young people so that this policy would be replaced with one that gives priority to stimulating employment on the labour market.

\section{REFERENCES}

1. A.P.Braica, Managementul resurselor umane, Editura "Vasile Goldis" University Press, Arad, 2009

2. V.Lefter, A.Manolescu, C.V.Marinas, A.Deaconu, Managementul resurselor umane, Editura ProUniversitaria, Bucuresti, 2012

3. A.Ticlea, L.Georgescu, Dreptul securitatii sociale. Curs universitar - Editia a IV-a, Editura Universul Juridic, Bucuresti, 2013

4. Law no. 335/2013 on internship for university graduates

5. Law no. 72/2007 on stimulating employment of pupils and students

6. Law no. $76 / 2002$ on the unemployment insurance system and stimulating employment, as amended and supplemented,

7. Law no. 62/2011 Law of Social Dialogue

8. G.D. no. 1071/2013 on the approval of the National Strategy for Employment 2014-2020 and the Action Plan for 2014-2020

9. The memorandum entitled: Approval of the Youth Guarantee Implementation of Plan 2014-2015, adopted in the Government Meeting of 23.12.2013

10. 2013 World Bank Report Europe 2020: Evidence-based Policies for Productivity, Employment, and Skills Enhancement

11. National Strategy for Employment, study conducted within the Transnational Partnership for Employment Promotion (EMPLO-NET) Project, the Sectorial Operational Programme Human Resources Development 2007-2013, Priority Axis 
Braica, A.P., (2015)

Managing the current situation of young people in national and European context in terms of their employment

PA 6 Promoting Social Inclusion, DMI: 6.4. Transnational Initiatives for an inclusive labour market, SOPHRD/98/6.4/S/64086

12. http://www.anofm.ro

13. http://www.cnp.ro

www.mts.ro/wpcontent/uploads/.../Strategie_22.10.2013_integrat_revOM.doc

14. http://www.fonduri-ue.ro

15. http://www.worldbank.org/content/dam/Worldbank/document/eca/romania/Ou tput\%20RO.pdf

16. http://ec.europa.eu/social/home.jsp?langId=ro 